\title{
Thermal Decomposition of Phosgene and Diphosgene
}

\author{
Juan-Carlos Lizardo-Huerta ${ }^{1}$, Baptiste Sirjean ${ }^{1}$, Laurent Verdier $^{2}$, René Fournet ${ }^{1}$, \\ Pierre-Alexandre Glaude ${ }^{1 *}$ \\ ${ }^{1}$ Laboratoire Réactions et Génie des Procédés, CNRS, Université de Lorraine, \\ 1 rue Grandville BP 2045154001 Nancy Cedex, France \\ ${ }^{2}$ DGA Maîtrise NRBC, Site du Bouchet, 5 rue Lavoisier, BP n³, 91710 Vert le Petit, France
}

\begin{abstract}
Phosgene $\left(\mathrm{COCl}_{2}\right)$ is a toxic compound used or formed in a wide range of applications. The understanding of its thermal decomposition for destruction processes or in the event of accidental fire of stored reserves is a major safety issue. In this study, a detailed chemical kinetic model for the thermal decomposition and combustion of phosgene and diphosgene is proposed for the first time. A large number of thermo-kinetic parameters were calculated using quantum chemistry and reaction rate theory. The model was validated against experimental pyrolysis data from the literature. It is predicted that the degradation of diphosgene is mainly ruled by a pericyclic reaction producing two molecules of phosgene, and, to a lesser extent, by a roaming radical reaction yielding $\mathrm{CO}_{2}$ and $\mathrm{CCl}_{4}$. Phosgene is much more stable than diphosgene under high-temperature conditions and its decomposition starts at higher temperatures. Decomposition products are $\mathrm{CO}$ and $\mathrm{Cl}_{2}$. An equimolar mixture of these latter can be considered as a surrogate of phosgene from the kinetic point of view, but the important endothermic effect of the decomposition reaction can lead to different behaviors, for instance in case of auto-ignition under high pressure and high temperature.
\end{abstract}




\section{Introduction and background}

Phosgene (carbonyl chloride $\mathrm{COCl}_{2}$ ) is an important industrial substance used in organic synthesis as highly reactive halogenation and acylation reagent for industrial production of insecticides, isocyanates, plastics, aniline dyes, and resins with an estimated production of almost 1 billion pounds per year. ${ }^{1-3}$ Liquid diphosgene (trichloromethyl chloroformate $\mathrm{ClC}(\mathrm{O})-\mathrm{O}-\mathrm{CCl}{ }_{3}$ ), has been used in laboratories as a substitute to phosgene because of its greater stability at room temperature compared to gaseous phosgene. ${ }^{4,5}$ Fire hazards associated with stored phosgene and diphosgene raise crucial security issues.

Phosgene and diphosgene are highly toxic compounds in case of inhalation exposures. Severe respiratory effects, including pulmonary oedema, pulmonary emphysema, and death have been reported for humans. Severe eye irritation and skin burns may also result from exposure. ${ }^{6}$ Chronic long-term exposure to phosgene has resulted in some tolerance to acute effects to humans but may also causes irreversible pulmonary damages, such as emphysema and fibrosis. ${ }^{7,8}$ Such levels of high toxicity have resulted in the use of phosgene as chemical warfare agents during the First World War. ${ }^{9}$ The mandatory destruction of chemical weapons stockpiles or unexploded ammunitions found in old battlefields (a 1996 NATO report ${ }^{10}$ estimated that over 10 million of chemical munitions were yet to be retrieved and destroyed in Europe alone) requires efficient and extremely safe processes. The thermal treatment of these toxics, with or without oxygen, is one the method of choice to address this problem and the knowledge of the kinetics of combustion becomes crucial.

In addition, phosgene can be formed by the combustion of chlorinated hydrocarbon such as poly(vinyl chloride), PVC, either in waste incineration or accidental fires. ${ }^{11}$ Combustion kinetic studies of trichloroethane $1,1,1-\mathrm{C}_{2} \mathrm{H}_{3} \mathrm{Cl}_{3}$ have experimentally shown that phosgene is formed directly in the gas phase with high yields. ${ }^{12,13}$ Studies on the thermal decomposition of $\mathrm{CH}_{3} \mathrm{Cl}^{14}$ and $\mathrm{CCl}_{4}{ }^{15}$ have demonstrated that there is a strong probability for the formation of the carbene $\mathrm{CCl}_{2}$ during polychloroalkane pyrolysis and combustion and, in the presence of excess $\mathrm{O}_{2}$, this carbene would yield a large concentration of phosgene and $\mathrm{O}$ atoms in a bimolecular reaction. ${ }^{16}$

The thermal destruction of phosgene and diphosgene have been investigated in few experimental works. ${ }^{16-20}$ The high-level of toxicity of this compound induces a high level of complexity for any experiments. Consequently, there is a considerable lack of knowledge on the behavior of this chemical under high-temperature conditions with or without oxygen. The first investigations on the thermal decomposition of phosgene were carried out in the 1920s. ${ }^{17,18}$ In 1930 , Bodenstein ${ }^{19}$ studied the thermal and photochemical synthesis of phosgene from $\mathrm{CO}$ and $\mathrm{Cl}_{2}$ and showed that phosgene is formed from temperatures ranging from 350 to $500^{\circ} \mathrm{C}$, and accompanied 
by the reverse reaction, leading to an equilibrium. In 1994, Lim and Michael ${ }^{16}$ have studied the thermal decomposition of phosgene in incident shock waves, at different pressures, for temperatures ranging between 1400 and $2000 \mathrm{~K}$. According to this study, the authors proposed that phosgene decomposes mainly by (1) $\mathrm{COCl}_{2}(+\mathrm{M}) \rightarrow \mathrm{COCl}+\mathrm{Cl}(+\mathrm{M})$ and $(2) \mathrm{COCl}_{2}(+\mathrm{M}) \rightarrow \mathrm{CO}+\mathrm{Cl}_{2}$ $(+\mathrm{M})$, with a branching percentage of 90.5 and $9.5 \%$, respectively. In 2000, Battin-Leclerc et al. ${ }^{20}$ have studied the thermal decomposition of phosgene and diphosgene in an isothermal close reactor at temperatures ranging between 250 and $530^{\circ} \mathrm{C}$ and an initial pressure of 25 Torr (0.033 bar). In this work, the authors used diphosgene as a precursor of phosgene, because the latter is known to be the major product of decomposition of diphosgene: diphosgene completely yields phosgene at about $450^{\circ} \mathrm{C}$. Starting from this temperature, the authors have measured the products of the thermal decomposition of phosgene.

These experimental studies of the literatures gave some insights on the thermal decomposition kinetics of phosgene and diphosgene at low pressures. However, to the best of our knowledge, no kinetic model has been proposed in the literature to understand and simulate these data. In this work, we followed a methodology established to simulate the thermal decomposition of yperite (sulfur mustard) ${ }^{21}$ and HN-3 (nitrogen mustard), ${ }^{22}$ to develop a detailed kinetic model for diphosgene and phosgene. The model is validated against available experimental data of the literature and allows to better understand phosgene and diphosgene thermal decomposition. In addition, a comparison of simulated ignition delay times of diphosgene, phosgene and a newly defined phosgene surrogate (mixture of $\mathrm{CO}$ and $\mathrm{Cl}_{2}$ ) is presented and discussed.

\section{Computational methods}

Theoretical calculations were used to elucidate the decomposition routes of diphosgene and to compute the kinetic data of several important reactions in the phosgene mechanism. The methodology involves the use of theoretical methods of quantum chemistry to predict the potential energy surfaces and statistical mechanics and reaction rate theory to calculate the high-pressure kinetic constants and thermochemical data $\left(\Delta_{\mathrm{f}} \mathrm{H}^{\circ}{ }_{298 \mathrm{~K}}, \mathrm{~S}^{\circ}{ }_{298 \mathrm{~K}}, \mathrm{C}^{\circ} \mathrm{P}(\mathrm{T})\right)$.

The CBS-QB3 level of theory ${ }^{23}$ has been used for the optimization of the structures and the calculation of the electronic energies. This composite method has been widely used in the literature and it provides an effective compromise between accuracy and computational time. It involves a geometry optimization and a frequency calculation at the B3LYP/6-311G(2d,d,p) level, and single point energy computations using several levels of theory with an extrapolation to the complete basis set limit. In addition, an analysis of the vibrational frequencies was systematically performed to confirm the nature of the transition states (TS). In cases where the imaginary frequency of the TS 
was not unambiguously related to the reaction coordinate, Intrinsic Reaction Coordinate (IRC) calculations ${ }^{24}$ were used to ensure that the optimized TS actually connected the desired reactant(s) and product(s). In this study, all the calculations have been performed using the GAUSSIAN09 Rev. B.01 software. ${ }^{25}$

For all species for which thermochemical data have been calculated, the enthalpies of formation were computed using atomization reaction energies. The high-pressure kinetic constants and the thermodynamic data were calculated using THERMROT. ${ }^{26}$ This in-house code allows a 1DHR-U treatment of internal rotations and has been modified to avoid the difficult choice of the low-frequency vibrations removing (regarded as internal rotations) by using a method proposed by Vansteenkiste et $a l .{ }^{27}$ 1-DHR treatment was used with torsional potential calculated from relaxed scans computed at the B3LYP/6-311G(2d,d,p) level of theory. The temperature dependent kinetic rate constants were fitted using the three parameter modified Arrhenius equation $\left(A \times T^{n} \times \exp (-\right.$ $\left.\mathrm{E}_{\mathrm{a}} / \mathrm{RT}\right)$ ) over the temperature range $300-2000 \mathrm{~K}$.

\section{Chemical Kinetic Model Development}

The detailed kinetic model for the thermal decomposition and high-temperature combustion of phosgene and diphosgene is composed of a comprehensive sub-mechanism dedicated to the specific reactions of phosgene, diphosgene, and derived products and another one related to the reactions of chlorinated species. The sub-mechanism for phosgene and diphosgene was developed in a comprehensive way following radical chain reaction scheme: initiation, propagation, and termination reaction were considered.

\subsection{Reactions of diphosgene}

Unimolecular decomposition reactions of diphosgene involve initial bond fissions and pericyclic reactions, which have been investigated systematically. The energies involve in the initial bond fissions, assimilated to the bond dissociation energies (BDE), are given in Figure 1. It can be seen that the weakest bonds are the $\mathrm{C}-\mathrm{Cl}$ and $\mathrm{C}-\mathrm{O}$ bonds in the aliphatic carbon side (BDE4 and BDE3 in Figure 1, respectively), whereas $\mathrm{C}-\mathrm{Cl}$ bond located on the carbonyl side implicates a much higher BDE and leads to a more difficult bond fission. The case of the unimolecular initiations involving the $\mathrm{C}-\mathrm{O}$ bond fission (BDE3) attracts a particular attention because this reaction leads to the formation of $\mathrm{CO}_{2}$ and $\mathrm{CCl}_{4}$ by a rearrangement reaction, typical of the thermal decomposition of chloroformates. ${ }^{28,29}$ This reaction can be explained by a roaming radical reaction, ${ }^{30}$ which occurs during radical-radical separation. The $\mathrm{C}-\mathrm{O}$ bond fission leads to the formation of two radicals, but as the radicals are separating, the chloromethyl fragment can rotate 
and abstract the $\mathrm{Cl}$-atom from the $\mathrm{Cl}-\mathrm{CO}_{2}$ fragment (barrierless reaction). The reaction eventually yields $\mathrm{CO}_{2}$ and $\mathrm{CCl}_{4}$. This reaction can explain early $\mathrm{CCl}_{4}$ formation at very low conversion of diphosgene, when the concentration is very low for the radicals promoting the $\mathrm{Cl}$-abstraction $(\mathrm{Cl}$ and $\mathrm{CCl}_{3}$ ). All of these initiation reactions were written in the reverse direction as radical combinations, which involve no energy barrier. The kinetic constants were estimated at high pressure limit using the EXGAS correlations ${ }^{31}$ based on analogies with similar reactions with welldefined kinetic parameters.

Possible unimolecular pericyclic reactions were considered by analogy with that of methyl formate, which decomposition has been thoroughly investigated in the literature. ${ }^{32-35}$ Methyl formate has indeed a structure close to that of diphosgene, with $\mathrm{H}$-atoms replacing $\mathrm{Cl}$-atoms. Three reactions can occur:

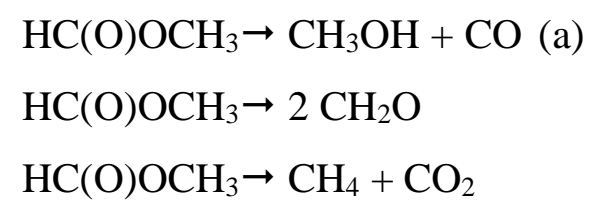

Both theoretical calculations ${ }^{33,34}$ and experiments in a shock tube ${ }^{35}$ found that reaction (a) yielding methanol and $\mathrm{CO}$ was, by far, the major products channel. From theoretical rate constants, calculated at high pressure limit by Metcalfe et al., ${ }^{34}$ the branching ratios at $1300 \mathrm{~K}$ are $99.6 \%$, $0.3 \%$, and $0.1 \%$ for reactions (a), (b) and (c), respectively, whereas measurements in shock tube between $1202 \mathrm{~K}$ and $1607 \mathrm{~K}$ under 1.3 to $1.7 \mathrm{~atm}^{35}$ led to branching ratios of $91.5 \%, 3.2 \%$, and $5.3 \%$ at $1300 \mathrm{~K}$, respectively. Similar reaction routes were investigated in the case of diphosgene. Transition states (TS) were searched with $a b$ initio and DFT methods, at the B3LYP/6$311 \mathrm{G}(2 \mathrm{~d}, \mathrm{~d}, \mathrm{p})$ and MP2/6-311+G(2d,p) levels of theory. In the case of diphosgene, the reaction channel (a) involves a 1,2-Cl-atom transfer from C- to-O-atom and no closed shell singlet TS could be found for this mechanism. The attempts made to optimize a TS for this channel systematically lead to dismutation saddle points featuring multi-reference characters with energy barriers higher than $100 \mathrm{kcal} \mathrm{mol}^{-1}$. Therefore, this reaction path was disregarded. No TS could neither be characterized in DFT nor in MP2 methods in the case of the reaction channel (c) consisting in a Clatom transfer to the $\mathrm{CCl}_{3}$ moiety yielding $\mathrm{CCl}_{4}$ and $\mathrm{CO}_{2}$. In both cases (a) and (c), it appears that the biggest size of the $\mathrm{Cl}$-atoms, compared to $\mathrm{H}$-atoms, and the associated longer bond lengths lead to geometries that prevent any easy concerted atom transfer in the molecule, leading to a different behavior of diphosgene compared to methyl formate. In the latter reaction, the leaving $\mathrm{Cl}$-atom cannot approach the $\mathrm{C}$-atom in $\mathrm{CCl}_{3}$, and tends rather to connect to another Cl-atom. A TS corresponding to a pericyclic reaction could eventually be found in the case of the reaction route equivalent to (b), at both B3LYP/6-311G(2d,d,p) and MP2/6-311+G(2d,p) levels of theories. This 
four-centered pericyclic reaction implies the rupture of the $\mathrm{C}-\mathrm{O}$ bond and an internal transfer of a Cl-atom to produce two molecules of phosgene:

\section{$\mathrm{ClC}(\mathrm{O}) \mathrm{OCCl}_{3} \rightarrow 2 \mathrm{COCl}$}

The CBS-QB3 structure of the TS is displayed in Figure 2. This reaction channel is consistent with experimental studies on diphosgene thermal decomposition, which observed phosgene as the main product $^{20}$, whereas decomposition of methyl formate leads mostly to methanol. ${ }^{32,35}$ Reporting the pericyclic reaction in Figure 1, it appears that the energy barrier of this reaction $\left(44.3 \mathrm{kcal} \mathrm{mol}^{-1}\right.$ at $298 \mathrm{~K}$ ) is well below the computed BDEs. The rate coefficients of the reaction have been obtained from the computation method described in $§ 2$ and are reported in Table 1.

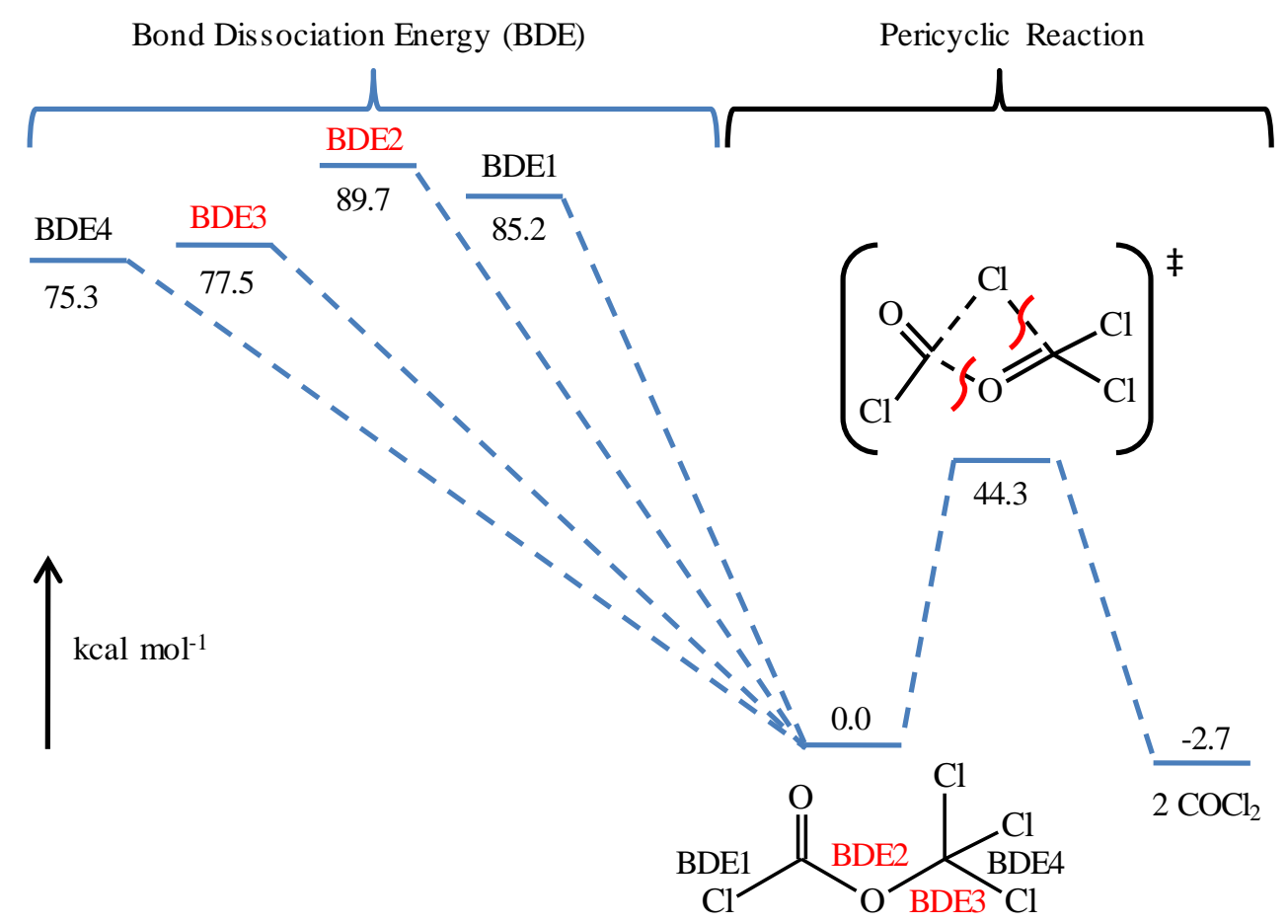

Figure 1. Bond dissociation energies and the energy barrier of the pericyclic reaction of diphosgene at $298 \mathrm{~K}$. The calculations have been performed at the CBS-QB3 level of theory and the energies are expressed in $\mathrm{kcal} \mathrm{mol}^{-1}$ 


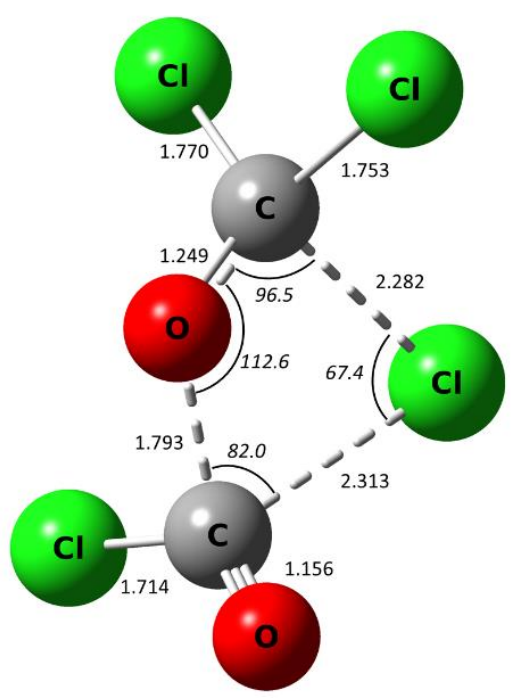

Figure 2. CBS-QB3 geometry (bond lengths in Á) of diphosgene transition state for the 4-centered pericyclic reaction; COCO dihedral angle is $121.5^{\circ}$.

In addition to unimolecular initiations, Cl-abstraction reactions by abundant radicals of the system $\left(\mathrm{CCl}_{3}\right.$ and $\left.\mathrm{Cl}\right)$ that cannot decompose by easy unimolecular reactions, such as $\beta$-scission reactions $\left(\beta\right.$-radicals $\left.{ }^{36}\right)$, have been included in the mechanism. The kinetic constants of these reactions are presented in Table 1. They were calculated theoretically at the CBS-QB3 level of theory following the methodology described above. In the case of the Cl-atom bounded to the carbonyl group, we have not been able to find a transition state and the kinetic parameters were consequently estimated by analogy with the $\mathrm{Cl}$-abstraction in phosgene as proposed by Leylegian $e t$ $a l .{ }^{37}$ in the sub-mechanism of the decomposition of chlorinated species. According to Table 1, we can observe that abstraction of the $\mathrm{Cl}$-atom bounded to the aliphatic carbon is easier than that bounded to the carbonyl group, which can be explained by the lower bond dissociation energy calculated in the first case (75.3 against $85.2 \mathrm{kcal} \mathrm{mol}^{-1}$ at $\left.298 \mathrm{~K}\right)$.

Table 1. High-pressure limit rate constants considered for unimolecular decomposition and Cl-abstraction in diphosgene. Units are $\mathrm{cm}^{3}$, mol, s, cal with $\mathrm{k}=\mathrm{A} \mathrm{T}^{\mathrm{n}} \exp (-\mathrm{E} / \mathrm{RT})$.

\begin{tabular}{lccccc} 
Reaction & $\mathrm{A}$ & $\mathrm{n}$ & $\mathrm{E}$ & $\mathrm{k}_{500 \mathrm{~K}}$ \\
\hline $\mathrm{ClC}(\mathrm{O})-\mathrm{O}-\mathrm{CCl}_{3} \leftrightarrows 2 \mathrm{COCl}_{2}$ & $9.73 \times 10^{14}$ & -0.333 & 44290 & $5.35 \times 10^{-6}$ & theory \\
\hline $\mathrm{ClC}(\mathrm{O})-\mathrm{O}-\mathrm{CCl}_{3}+\mathrm{Cl} \leftrightarrows \mathrm{ClC}(\mathrm{O})-\mathrm{O}-\mathrm{CCl}_{2}+\mathrm{Cl}_{2}$ & $4.85 \times 10^{9}$ & 1.590 & 14680 & $3.63 \times 10^{7}$ & theory \\
\hline $\mathrm{ClC}(\mathrm{O})-\mathrm{O}-\mathrm{CCl}_{3}+\mathrm{Cl} \leftrightarrows \mathrm{C}(\mathrm{O})-\mathrm{O}-\mathrm{CCl}_{3}+\mathrm{Cl}_{2}$ & $3.20 \times 10^{14}$ & 0.0 & 23500 & $1.71 \times 10^{4}$ & analogy ref. 33 \\
\hline $\mathrm{ClC}(\mathrm{O})-\mathrm{O}-\mathrm{CCl}_{3}+\mathrm{CCl}_{3} \leftrightarrows \mathrm{ClC}(\mathrm{O})-\mathrm{O}-\mathrm{CCl}_{2}+\mathrm{CCl}_{4}$ & $5.12 \times 10^{2}$ & 3.086 & 13610 & $1.23 \times 10^{5}$ & theory \\
\hline $\mathrm{ClC}(\mathrm{O})-\mathrm{O}-\mathrm{CCl}_{3}+\mathrm{CCl}_{3} \leftrightarrows \mathrm{C}(\mathrm{O})-\mathrm{O}-\mathrm{CCl}_{3}+\mathrm{CCl}_{4}$ & $8.78 \times 10^{6}$ & 1.780 & 22850 & $5.74 \times 10^{1}$ & theory \\
\hline
\end{tabular}


The decomposition reactions of the radicals formed during the $\mathrm{Cl}$-abstraction reactions from diphosgene were also included in the propagation reactions. The reactions considered involve $\alpha$ and $\beta$-scissions. The rate constants of these reactions, computed at the CBS-QB3 level of theory, are shown in Table 2.

Table 2. High-pressure limit rate constants calculated at the CBS-QB3 level of theory for the $(\alpha, \beta)$-scissions in diphosgene radicals. Units are $\mathrm{cm}^{3}$, mol, $\mathrm{s}$, cal with $\mathrm{k}=\mathrm{A} \mathrm{T}^{\mathrm{n}} \exp (-\mathrm{E} / \mathrm{RT})$.

\begin{tabular}{lcccc} 
Reaction & A & $n$ & $\mathrm{E}$ & $\mathrm{k}_{500 \mathrm{~K}}$ \\
\hline $\mathrm{ClC}(\mathrm{O})-\mathrm{O}-\mathrm{CCl}_{2} \leftrightarrows \mathrm{COCl}_{2}+\mathrm{CClO}$ & $5.20 \times 10^{12}$ & 0.495 & 17690 & $2.08 \times 10^{6}$ \\
\hline $\mathrm{C}(\mathrm{O})-\mathrm{O}-\mathrm{CCl}_{3} \leftrightarrows \mathrm{CCl}_{3}+\mathrm{CO}_{2}$ & $2.75 \times 10^{14}$ & -0.322 & 21240 & $1.93 \times 10^{4}$ \\
\hline $\mathrm{C}(\mathrm{O})-\mathrm{O}-\mathrm{CCl}_{3} \leftrightarrows \mathrm{CCl}_{3} \mathrm{O}+\mathrm{CO}$ & $1.27 \times 10^{12}$ & 0.629 & 16510 & $3.84 \times 10^{6}$ \\
\hline
\end{tabular}

The products formed in Table 2 are mainly chlorinated species as well as $\mathrm{CO}$ and $\mathrm{CO}_{2}$ which react in a specific reactions database described below. In addition to this primary mechanism of diphosgene thermal decomposition, a detailed mechanism of the decomposition of phosgene was written in this work.

\subsection{Reactions of phosgene}

Phosgene can react through unimolecular decomposition reactions (reactions (2) and (3)) involving a bond fission for the first reaction (bond dissociation energy $\mathrm{ClCO}-\mathrm{Cl}$ of $77.6 \mathrm{kcal} \mathrm{mol}^{-}$ $\left.{ }^{1}\right)$ and a 3 -centered molecular elimination for the second.

$\mathrm{COCl}_{2}=\mathrm{CClO}+\mathrm{Cl}$

$\mathrm{COCl}_{2}=\mathrm{CO}+\mathrm{Cl}_{2}$

An interesting question concerns the branching ratio and the pressure effect on these two reactions. Their kinetic data were measured by Lim and Michael. ${ }^{16}$ The authors have studied the thermal decomposition of $\mathrm{COCl}_{2}$ in incident shock wave. The produced Cl-atoms were monitored using atomic resonance absorption spectrometry (ARAS), for three different loading pressures, over temperatures ranging from 1400 to $2000 \mathrm{~K}$. In this work, the authors proposed the high-pressure $\left(\mathrm{k}_{\infty}\right)$ and the low-pressure $\left(\mathrm{k}_{0}\right)$ limit kinetic constants and the parameters for the theoretical evaluation of rate constants as a function of the pressure. From these data, we calculated from a mathematical fit the fall-off parameters in Troe formalism. ${ }^{38}$ The results are presented in Table 3. 
Table 3. Pressure dependent rate constants in Troe formalism derived from from Lim and Michael ${ }^{16}$. Units are $\mathrm{cm}^{3}$, mol, s, cal with $\mathrm{k}=\mathrm{A} \mathrm{T}^{\mathrm{n}} \exp \left(-\mathrm{E}_{\mathrm{a}} / \mathrm{RT}\right)$.

\begin{tabular}{cccccc}
$\begin{array}{c}\text { Reactio } \\
\mathrm{n}\end{array}$ & $\begin{array}{c}\text { Pressure- } \\
\text { limit }\end{array}$ & $\mathrm{A}$ & $\mathrm{n}$ & $\mathrm{E}_{\mathrm{a}}$ & Troe's fall-off parameters (a T*** $\left.\mathrm{T}^{*}\right)$ \\
\hline \multirow{2}{*}{$(1)$} & High & $5.71 \times 10^{15}$ & 0 & 72330 & 0.32620 .03052 .0 \\
\cline { 2 - 5 }$(2)$ & Low & $2.80 \times 10^{17}$ & 0 & 61760 & 0.70320 .03840 .0 \\
\cline { 2 - 5 } & High & $1.45 \times 10^{14}$ & 0 & 82470 & 0 \\
\hline
\end{tabular}

Figure 3 presents the evolution of unimolecular decomposition branching ratios of phosgene, as a function of pressure, for temperatures ranging from 1200 to $1500 \mathrm{~K}$. Above 1 bar, branching ratios are nearly pressure independent $\left(\mathrm{k}_{\mathrm{inf}}\right)$ for the temperature range studied. As pressure decreases, the initial $\mathrm{C}-\mathrm{Cl}$ bond fission in phosgene (reaction (2)) is favored over the elimination of $\mathrm{Cl}_{2}$ (reaction (3)). A pressure drop from 1 to 0.01 bar, leads to an increase of the $\mathrm{CClO}+\mathrm{Cl}$ channel yield, from 1.2 to $66.5 \%$ at $1400 \mathrm{~K}$, while the branching ratio of $\mathrm{CO}+\mathrm{Cl}_{2}$ falls from 98.8 to $33.5 \%$. Within this semi-quantitative treatment of pressure effects in the thermal decomposition of phosgene, it is shown that at atmospheric pressure and above, using high-pressure limit rate constants should be a good approximation. Nevertheless for pressures below 1 bar, the effect of the pressure on the product branching ratios remains important.

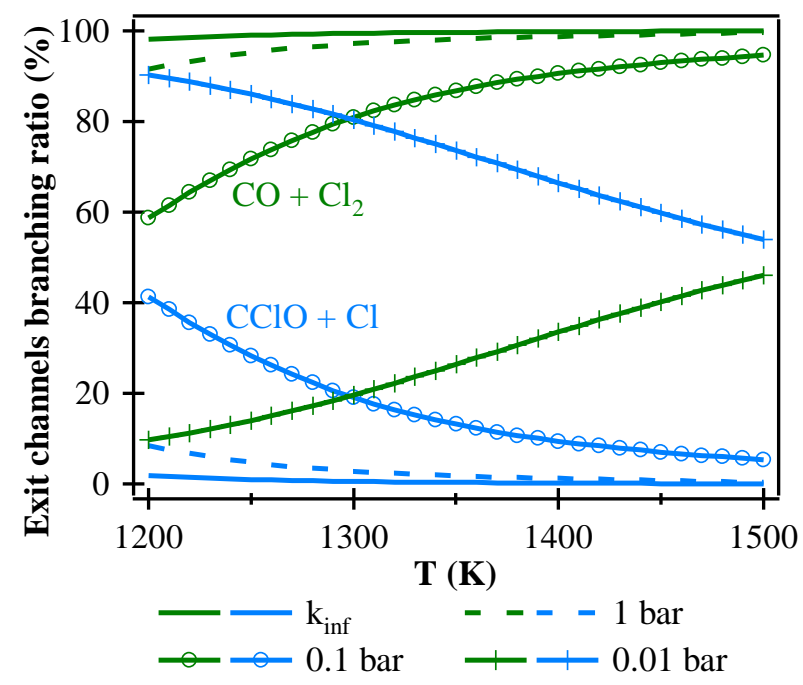

Figure 3. Branching ratios of $\mathrm{COCl}_{2}$ unimolecular decomposition as a function of temperature computed at various pressures.

Propagation reactions involving $\mathrm{Cl}$-abstraction by $\mathrm{Cl}$ and $\mathrm{O}$-atoms were included in the mechanism of phosgene decomposition with rate constants taken from the work of Leylegian et al. ${ }^{37}$ Addition of $\mathrm{O}$-atom on the double bond of $\mathrm{COCl}_{2}$ has been considered by analogy with the reaction of formaldehyde, with rate coefficients proposed by Dean and Kistiakowsky. ${ }^{39}$ The mechanism also 
implies some coupling reactions between products from phosgene and diphosgene, like Clabstraction reactions by the $\mathrm{CCl}_{3}$ radicals. The rate coefficients for propagations reactions are summarized in Table 4. The Cl-abstraction with $\mathrm{CCl}_{3}$ has been calculated using the CBS-QB3 method.

Table 4. High-pressure limit rate constants calculated for $\mathrm{Cl}$-abstraction from phosgene and O-atom addition on the double bond. Units are $\mathrm{cm}^{3}$, mol, s, cal with $\mathrm{k}=\mathrm{A} \mathrm{T}^{\mathrm{n}} \exp (-\mathrm{E} / \mathrm{RT})$.

\begin{tabular}{lcccc} 
Reaction & $\mathrm{A}$ & $\mathrm{n}$ & $\mathrm{E}$ & $\mathrm{k} 500 \mathrm{~K}$ \\
\hline $\mathrm{COCl}_{2}+\mathrm{Cl} \leftrightarrows \mathrm{CClO}+\mathrm{Cl}_{2}$ & $3.20 \times 10^{14}$ & 0.0 & 23500 & $1.71 \times 10^{4}$ \\
\hline $\mathrm{COCl}_{2}+\mathrm{O} \leftrightarrows \mathrm{CClO}+\mathrm{ClO}$ & $2.0 \times 10^{13}$ & 0.0 & 17000 & $7.41 \times 10^{5}$ \\
\hline $\mathrm{COCl}_{2}+\mathrm{CCl}_{3} \leftrightarrows \mathrm{CClO}+\mathrm{Cl}_{2} \mathrm{CCl}_{4}$ & $6.09 \times 10^{01}$ & 3.206 & 16100 & $2.51 \times 10^{3}$ \\
\hline $\mathrm{COCl}_{2}+\mathrm{O} \rightarrow \mathrm{ClO}+\mathrm{CO}+\mathrm{Cl}$ & $6.310^{13}$ & 0.0 & 0.0 & $6.03 \times 10^{13}$ \\
\hline
\end{tabular}

\subsection{Reactions of chlorinated species}

The thermal decomposition of phosgene and disphosgene leads to $\mathrm{C}_{0}-\mathrm{C}_{2}$ chlorinated species (molecules and radicals) and their reactions have been taken into account in this work. These reactions are mainly composed of those proposed by Leylegian et al. ${ }^{37}$ for the combustion of chloromethanes and validated against experimental laminar flame structures. We have also included some reactions involved in the model recently developed by Pelucchi et al. ${ }^{40}$ for $\mathrm{HCl}$ combustion, which updates the mechanism of the chlorinated species of Leylegian et al. and re-examines the mechanism of flame inhibition involving the $\mathrm{HCl} / \mathrm{Cl}_{2}$ system. We added all the reactions not included in the model by Leylegian and updated kinetic data of some reactions that appeared in both mechanisms.

\section{Results and discussion}

The detailed kinetic model for the thermal decomposition and the combustion of phosgene and diphosgene, developed in this work, was used to simulate the reaction of diphosgene and phosgene in a close vessel using the Chemkin II program suite. ${ }^{41}$ Simulations were performed under pyrolysis and combustion conditions and compared to available experimental results for validation.

\subsection{Pyrolysis of diphosgene}

The simulation conditions for the pyrolysis of diphosgene were taken from the experimental work carried out by Battin-Leclerc et al. $^{20}$ for the thermal decomposition of phosgene and diphosgene. The simulations were performed for temperatures ranging from 250 to $500^{\circ} \mathrm{C}$, the 
volume of the batch reactor was $350 \mathrm{~cm}^{3}$, the initial pressure was set at 25 Torr $(0.033$ bar $)$ and the residence time was kept constant at 10 minutes.

Figure 4 shows the evolution of the partial pressures of the products measured experimentally as a function of the temperature, for a residence time of $10 \mathrm{~min}$. In this figure, we can observe that the simulations are in good agreement with the experimental results for the main products, i.e. phosgene, $\mathrm{CO}$, and $\mathrm{CCl}_{4}$. The experimental partial pressures of phosgene are well reproduced by the model. This species is the major decomposition product of diphosgene and is mainly formed by the addition-elimination pericyclic reaction. For this residence time, a total conversion of diphosgene to phosgene is achieved around $330^{\circ} \mathrm{C}$ in simulation. Phosgene partial pressure is then close to twice the initial pressure of diphosgene, in accordance with the reaction stoichiometry. Phosgene has a very good thermal stability and is almost unreactive up to $450^{\circ} \mathrm{C}$. At higher temperature, phosgene starts to react and produces $\mathrm{CO}$ and $\mathrm{Cl}_{2}$. Note that the reactive $\mathrm{Cl}_{2}$ molecules were not quantified in the experiments. The simulations of minor products $\left(\mathrm{CCl}_{4}\right.$ and $\left.\mathrm{CO}\right)$ profiles are in very good agreement at all temperatures. The partial pressure of $\mathrm{CCl}_{4}$ increases almost linearly with temperature. This can be related to the minor decomposition pathway of diphosgene by the roaming reaction yielding $\mathrm{CCl}_{4}$ and $\mathrm{CO}_{2}$, which ratio increases with temperature. Partial pressure of $\mathrm{CO}$ remain negligible up to $450^{\circ} \mathrm{C}$, then increases strongly. This behavior is related to the onset of the decomposition of phosgene.

Experiments were performed in a Pyrex glass reactor, and questions can be raised on the wall catalytic effects on the kinetic measurements. Indeed, it is well known that chlorinated species are prone to interact with surfaces. ${ }^{42}$ The catalytic action of Pyrex can be accounted for by the polar surface facilitating the separation of charges within the carbon-chlorine bond. However, experiments seem to be little affected by heterogeneous reactions in this work. Diphosgene decomposed mostly by the pericyclic reaction to phosgene and no evidence of radical reactions initiated at the wall can be seen, until temperatures at which phosgene begins to decompose. The model predicts fairly well the temperature corresponding to phosgene decomposition and $\mathrm{CO}$ formation, with gas phase rate constants measured by Lim and Michael. ${ }^{16}$ Therefore, wall catalytic phenomena seem to have a negligible effect here. 


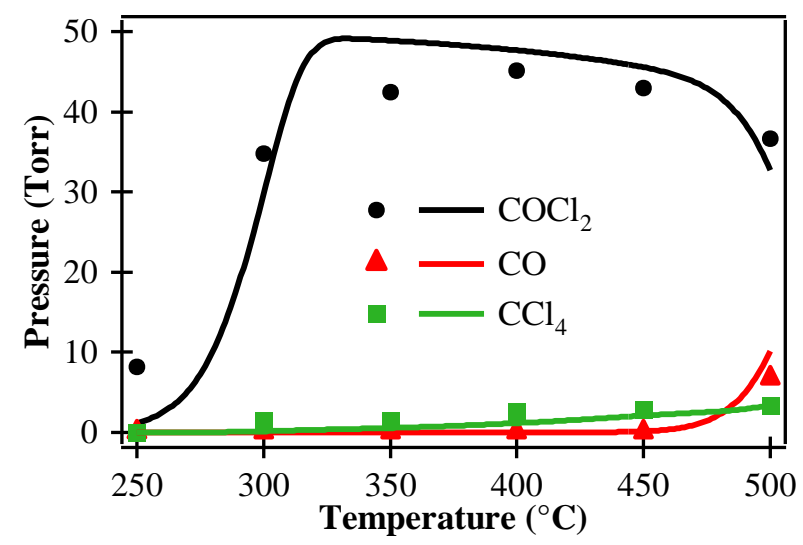

Figure 4. Products quantified during the thermal decomposition of diphosgene $v s$. temperature. Initial pressure, 25 Torr; residence time, $10 \mathrm{~min}$; symbols: experimental results $;{ }^{20}$ lines: simulation.

\subsection{Pyrolysis of phosgene}

In the experimental work by Battin-Leclerc et al. ${ }^{20}$ the authors studied the pyrolysis of phosgene using diphosgene as a precursor of phosgene. As shown above, the former decomposes completely to phosgene in a very short time at temperature above $330^{\circ} \mathrm{C}$. The authors have studied the pyrolysis of phosgene at 470,500 , and $530^{\circ} \mathrm{C}$ (maximum temperature reached with a Pyrex glass reactor), for an initial pressure of 25 Torr of diphosgene $(0.033$ bar $)$ and residences times ranging from 0 to $60 \mathrm{~min}$.

Figure 5 shows the evolution of the total pressure and the partial pressures of phosgene and $\mathrm{CO}$ as a function of the residence time for temperatures of 470,500 , and $530^{\circ} \mathrm{C}$. The simulations are in very good agreement with the experimental results. For all the temperatures studied, the total pressure instantaneously reaches 50 Torr, which implies that diphosgene has been completely decomposed and that the starting reactant is effectively phosgene. A gradual increase in total pressure implies that phosgene is decomposing until a maximum total pressure of 100 Torr, which correspond to a complete decomposition of phosgene, mainly to $\mathrm{CO}$ and $\mathrm{Cl}_{2}$. Note that $\mathrm{CO}$ partial pressure was experimentally recorded only at $500^{\circ} \mathrm{C}$. The model reproduces very well the experimental profile of $\mathrm{CO}$ in Figure 4b. Both experimental and simulated profiles illustrate well the conversion of phosgene to carbon monoxide, which is by far the most important carbon product resulting from the decomposition of phosgene. 

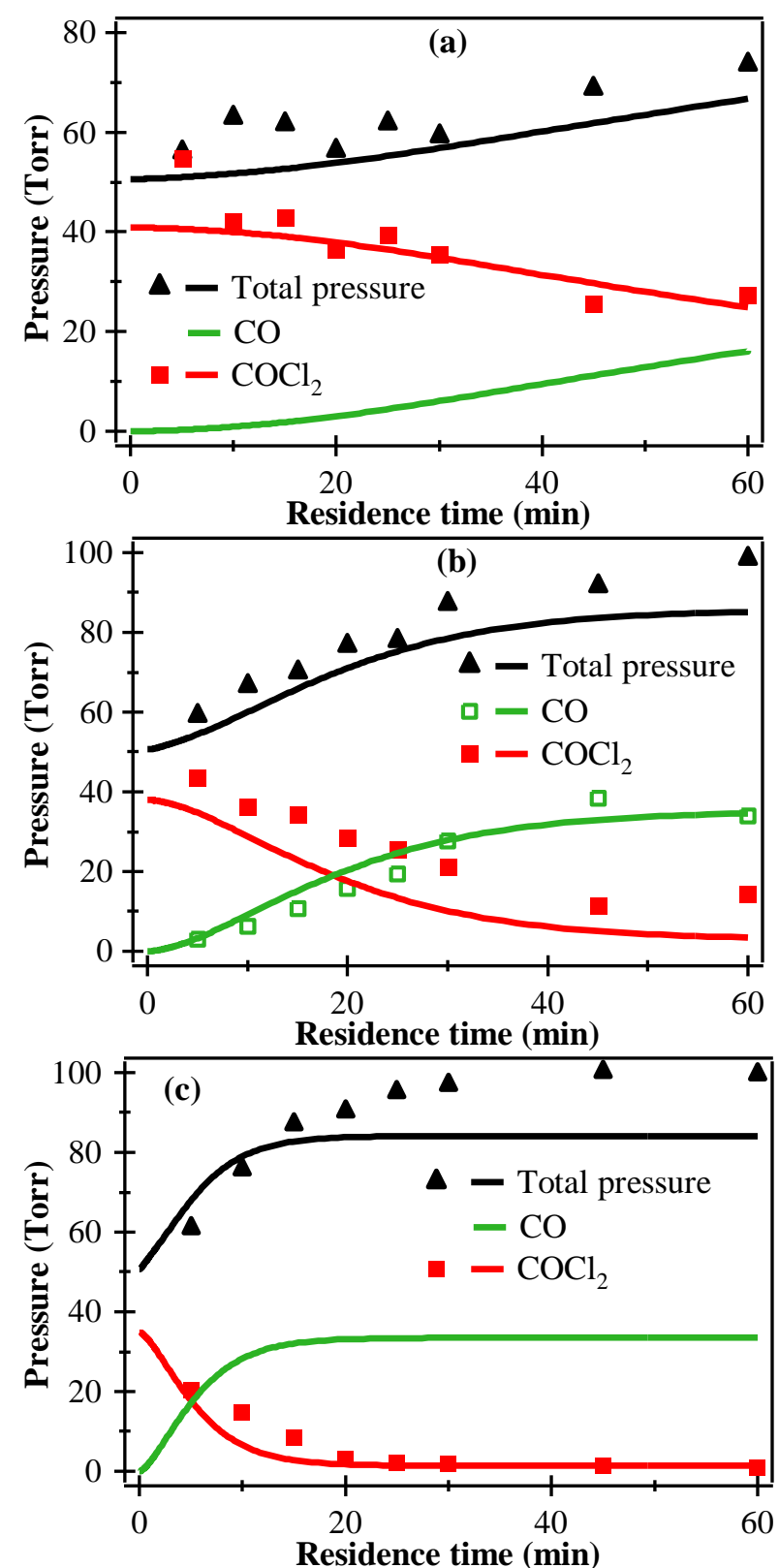

Figure 5. Evolution of the total pressure and the partial pressure of $\mathrm{COCl}_{2}$ and $\mathrm{CO}$ with residence time during the thermal decomposition of diphosgene at (a) $470^{\circ} \mathrm{C}$, (b) $500^{\circ} \mathrm{C}$ and (c) $530^{\circ} \mathrm{C}$. Initial pressure, 25 Torr of diphosgene; symbols: experimental results; ${ }^{20}$ lines: simulations.

\subsection{Reaction flux analysis}

Figure 6 presents a reaction flux analysis in the case of the pyrolysis of diphosgene at $400^{\circ} \mathrm{C}$. Diphosgene is mainly decomposed by the 4-membered pericyclic reaction yielding two molecules of phosgene and by the roaming radical reaction into small fraction of $\mathrm{CO}_{2}$ and $\mathrm{CCl}_{4}$. The role of this latter pathway increases with the temperature, accounting for $1.8 \%, 4 \%, 9 \%$, and $24 \%$ of diphosgene consumption at $300 \mathrm{~K}, 350 \mathrm{~K}, 400 \mathrm{~K}$, and $500 \mathrm{~K}$, respectively. The formation of these species was observed during the pyrolysis of diphosgene as a function of the temperature (Figure 4). Concerning reactions of phosgene, the only sensitive reactions are the initial bond breaking and the $\mathrm{Cl}$-atom abstractions. The reaction flux analysis shows that the decomposition of phosgene is 
mainly due to $\mathrm{Cl}$-abstraction by $\mathrm{Cl}$-atoms $(70 \%)$ and $\mathrm{CCl}_{3}$ radicals $(28 \%)$, forming the $\mathrm{CClO}$ radical. Finally, $\mathrm{CClO}$ decomposes by $\alpha$-scission into $\mathrm{CO}$ and $\mathrm{Cl}$. In the conditions of Figure 4, at $400^{\circ} \mathrm{C}$, phosgene is thermally stable and reacts very slowly. The onset of the decomposition of phosgene is observed above $450^{\circ} \mathrm{C}$ and the profile of $\mathrm{CO}$ increases then significantly. At all temperatures, $\mathrm{COCl}_{2}$ reacts mainly by $\mathrm{Cl}$-atom abstractions by $\mathrm{Cl}$-atoms and $\mathrm{CCl}_{3}$ radicals, yielding $\mathrm{Cl}_{2}$ and $\mathrm{CCl}_{4}$, respectively.

In the experiments on phosgene pyrolysis, presented in Figure 5, the authors assumed that 25 Torr of diphosgene would solely yields 50 Torr of phosgene above $470 \mathrm{~K}^{20}$. However, it can be noticed in Figure 4 that at higher temperatures (above $450^{\circ} \mathrm{C}$ ) the branching ratio of the channel $\mathrm{CCl}_{4}+\mathrm{CO}$ is not negligible. In order to check the influence of this minor channel on the conversion of phosgene, simulation were performed with pure phosgene (initial partial pressure of 50 Torr) and compared to that of phosgene produced from diphosgene (25 Torr initial pressure of diphosgene) in the conditions of Figure 5. At the same temperature, simulations showed a greater reactivity of pure phosgene. For a residence time of $10 \mathrm{~min}$, conversion of pure phosgene reached $25 \%$, 64\%, and $94 \%$, at $470^{\circ} \mathrm{C}, 500^{\circ} \mathrm{C}$, and $530^{\circ} \mathrm{C}$, respectively, whereas phosgene obtained from the dissociation of diphosgene was converted to $4.3 \%, 36 \%$, and $88 \%$, respectively. The difference is due to minor products of diphosgene dissociation, mainly $\mathrm{CO}_{2}$ and $\mathrm{CCl}_{4}$, which inhibit the radical reaction. In the case of pure phosgene, $\mathrm{Cl}$-atoms are the only chain carrier and propagate the reaction by abstracting another $\mathrm{Cl}$-atom from the reactant. When diphosgene is the reactant, small amounts of $\mathrm{CCl}_{4}$ are produced together with phosgene. Cl-atoms react with $\mathrm{CCl}_{4}$ yielding the less reactive $\mathrm{CCl}_{3}$ radicals. These latter can react slowly with phosgene but also in radical-radical combinations producing chlorinated $\mathrm{C}_{2}$, which lead to a loss of reactive species and a lessening of the reactivity.

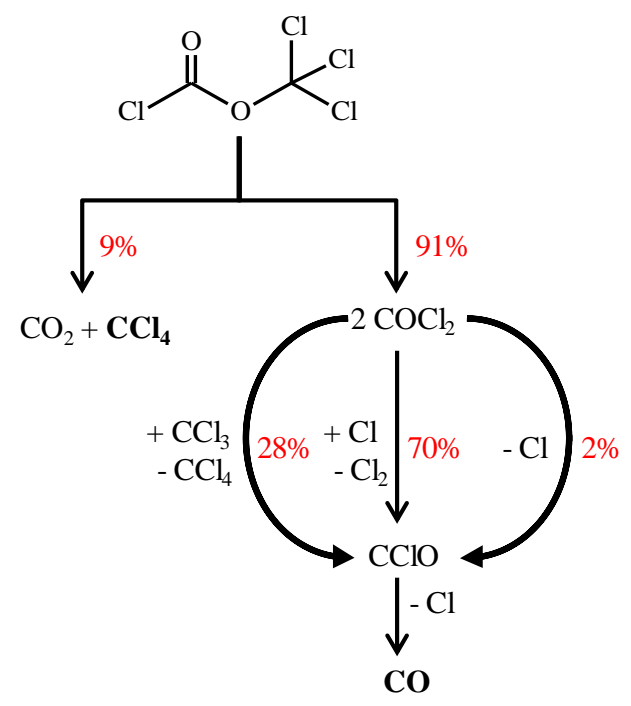

Figure 6. Reaction flux analysis for the pyrolysis of diphosgene. Initial pressure, 25 Torr; residence time, $1 \mathrm{~s}$ (corresponding to $50 \%$ of diphosgene conversion). 


\subsection{Auto-ignition delay times of phosgene, $\mathrm{CO}$ and $\mathrm{CO} / \mathrm{Cl}_{2}$ mixture in air}

Accidental fires or waste incineration can involve phosgene. It appears also as an important by-products during chlorinated hydrocarbons or polymer combustion. In order to assess the reactivity of phosgene in the presence of oxygen, ignition delay times in air were simulated in an isochoric homogenous reactor for temperatures ranging from 1000 to $2000 \mathrm{~K}$ and an initial pressure of 10 bar. Simulations were effectuated in air at a stoichiometric equivalence ratio for three mixtures: $\mathrm{COCl}_{2}$ /air, $\mathrm{CO}$ /air, and $\mathrm{CO} / \mathrm{Cl}_{2}$ /air. The second mixture allowed to compare phosgene reactivity to that of carbon monoxide, which is the main combustible product of decomposition of $\mathrm{COCl}_{2}$. The last mixture was designed to represent full products of thermal decomposition of phosgene and could be used to define a surrogate for phosgene. It also allows to test the influence of $\mathrm{Cl}_{2}$ on the reactivity of $\mathrm{CO}$. Figure $7 \mathbf{a}$ presents the auto-ignition delay times obtained using the detailed kinetic model developed in this work. Figure $\mathbf{7 b}$ displays the profiles of temperature and species as a function of time in the case of the $\mathrm{COCl}_{2}$ /air mixture at an initial temperature of $1300 \mathrm{~K}$. It appears that phosgene induces the longest ignition delay time, pure $\mathrm{CO}$ has a shorter ignition delay time than phosgene but the mixture $\mathrm{CO} / \mathrm{Cl}_{2}$ leads to the fastest ignition.

The low reactivity of phosgene in auto-ignition is actually due to the fast endothermic decomposition of $\mathrm{COCl}_{2}$, which leads to a dramatic drop of the temperature. Initiations are mainly due to unimolecular $\mathrm{CO}-\mathrm{Cl}$ bond breaking $\left(\mathrm{BDE} 77.6 \mathrm{kcal} \mathrm{mol}^{-1}\right)$; phosgene reacts thereafter with $\mathrm{Cl}$-atoms yielding $\mathrm{Cl}_{2}$ and $\mathrm{COCl}$. This latter decomposes fast to $\mathrm{CO}$ and $\mathrm{Cl}$-atoms, which are chain carriers. The global reaction $\mathrm{COCl}_{2}=\mathrm{CO}+\mathrm{Cl}_{2}$ is endothermic by $25.1 \mathrm{kcal} \mathrm{mol}^{-1}$ at $1300 \mathrm{~K}$. In the conditions of Figure $\mathbf{7 b}$, about $60 \%$ of initial phosgene decomposes during the first seconds of the reaction. The thermal effect of the reaction leads to a temperature dropping from $1300 \mathrm{~K}$ to about $840 \mathrm{~K}$. The reaction is then frozen. The slow oxidation of $\mathrm{CO}$ with oxygen to produce $\mathrm{CO}_{2}$ starts then. $\mathrm{Cl}_{2}$ also reacts with oxygen to form $\mathrm{ClO}$, which reacts with $\mathrm{CO}$ to form $\mathrm{CO}_{2}$. These exothermic reactions eventually cause an increase of temperature and an auto-ignition at a residence time of $37 \mathrm{~s}$. The long ignition delay time of phosgene is due to the competition between the fast endothermic decomposition of the reactant and the somewhat slow exothermic oxidation of the main products. Thermal evolution of the mixture explains the difference in the behavior compared to $\mathrm{CO}$ and $\mathrm{CO} / \mathrm{Cl}_{2}$ blends. 

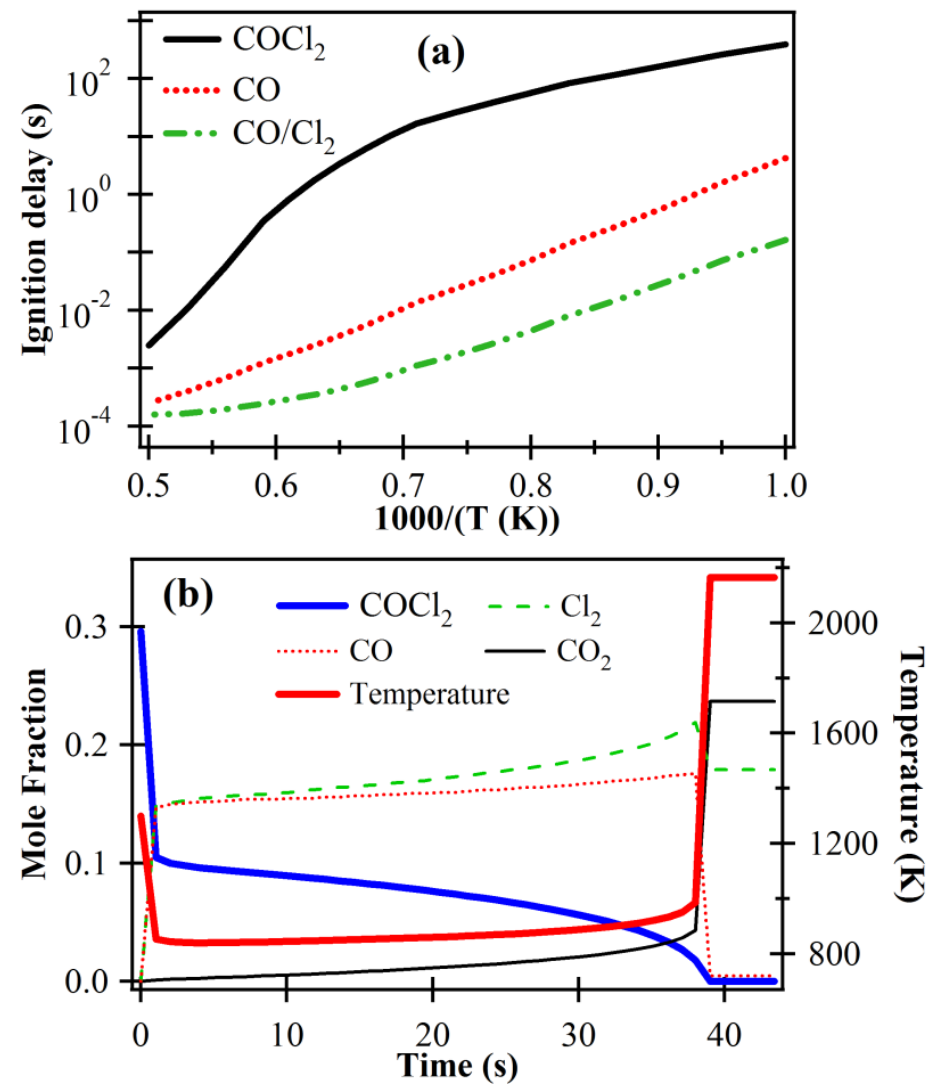

Figure 7. (a) Ignition delay times for stoichiometric fuel/air mixtures in an isochoric homogenous reactor at 10 bar initial pressure, and (b) temperature and species profiles for $\mathrm{COCl}_{2} /$ air mixture at an initial temperature of $1300 \mathrm{~K}$.

Mixtures of $\mathrm{CO} /$ air and $\mathrm{CO} / \mathrm{Cl}_{2} /$ air lead to shorter auto-ignition delays because of the absence of an endothermal reaction causing a temperature drop, as in the phosgene mixture. The oxidation reactions involved during the oxidation of these blends are presented in the Table 5. It appears that $50 \%$ of initial $\mathrm{CO}$ reacts with molecular oxygen to produce $\mathrm{CO}_{2}$ and one O-atom, whereas the other $50 \%$ of $\mathrm{CO}$ react with the oxygen atom formed to produce $\mathrm{CO}_{2}$. In presence of $\mathrm{Cl}_{2}, \mathrm{CO}$ is no longer directly oxidized into $\mathrm{CO}_{2}$ by molecular oxygen. $\mathrm{Cl}_{2}$ acts as a homogeneous catalyst, which reacts with molecular oxygen to produce a radical intermediate, $\mathrm{ClO}$, which reacts with $\mathrm{CO}$ to form $\mathrm{CO}_{2}$ and a $\mathrm{Cl}$-atom. $\mathrm{Cl}$-atoms mostly add to $\mathrm{CO}$ to produce $\mathrm{CClO}$. The latter reacts with another $\mathrm{Cl}$-atom and regenerate $\mathrm{Cl}_{2}$ and $\mathrm{CO}$, or to a lesser extent, with $\mathrm{O}_{2}$ to produce $\mathrm{CO}_{2}$ and $\mathrm{ClO}$. Note that a small fraction of $\mathrm{CClO}$ can combine with chlorine atoms to yield phosgene, as seen during chloromethane combustion. $^{43}$ 
Table 5. Reactions involved in the decomposition of the mixtures $\mathrm{CO} / \mathrm{air}$ and $\mathrm{CO} / \mathrm{Cl}_{2} / \mathrm{air}$.

\begin{tabular}{lll} 
CO/air & $\mathbf{C O} / \mathrm{Cl}_{2} /$ air \\
\hline $\mathrm{CO}+\mathrm{O}_{2}=\mathrm{CO}_{2}+\mathrm{O}$ & $(50 \%)$ & $\mathrm{Cl}_{2}+\mathrm{O}_{2}=2 \mathrm{ClO}$ \\
$\mathrm{CO}+\mathrm{O}=\mathrm{CO}_{2}$ & $(50 \%)$ & $2 \mathrm{ClO}+2 \mathrm{CO}=2 \mathrm{CO}_{2}+2 \mathrm{Cl}$ \\
& & $2 \mathrm{Cl}+\mathrm{CO}=\mathrm{Cl}_{2}+\mathrm{CO}$ \\
Global reaction: $2 \mathrm{CO}+\mathrm{O}_{2}=2 \mathrm{CO}_{2}$ & Global reaction: $2 \mathrm{CO}+\mathrm{Cl}_{2}+\mathrm{O}_{2}=2 \mathrm{CO}_{2}+\mathrm{Cl}_{2}$ \\
\hline
\end{tabular}

To illustrate the favorable reaction of chlorine with molecular oxygen compared to $\mathrm{CO}$, Figure 8 displays the branching ratio for the oxidation reaction of $\mathrm{Cl}_{2}$ and $\mathrm{CO}$, based on their kinetic constants, in an equimolar $\mathrm{CO} / \mathrm{Cl}_{2}$ blend. We can observe that the oxidation on $\mathrm{Cl}_{2}$ is much more favorable and increases even more as the temperature increases.

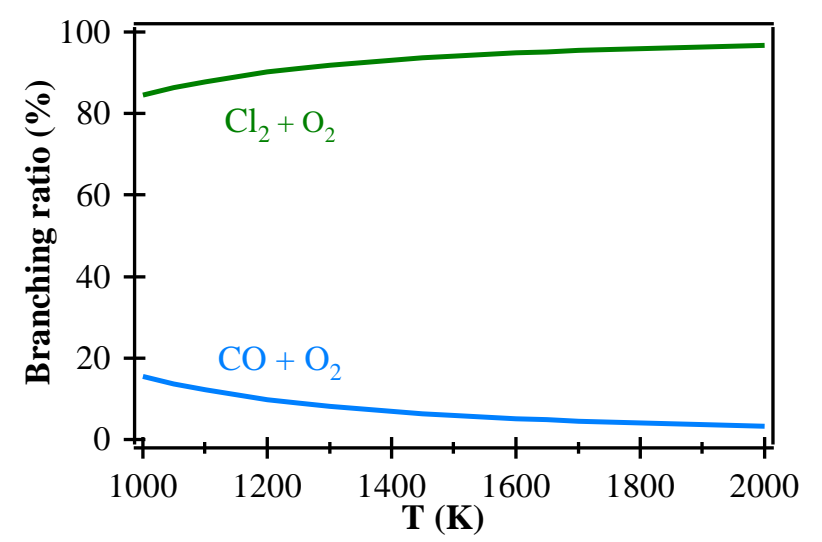

Figure 8. Branching ratios for the oxidation reaction of $\mathrm{Cl}_{2}$ and $\mathrm{CO}$ as a function of the temperature.

In so far, as differences in self-ignition behavior in the adiabatic close vessel between phosgene and $\mathrm{CO}$ and $\mathrm{CO} / \mathrm{Cl}_{2}$ blends were mostly influenced by thermal effects, simulations were performed in an isothermal continuous stirred reactor to assess chemical kinetic influence on reactivity. Stoichiometric oxidation of phosgene, $\mathrm{CO}$ and $\mathrm{CO} / \mathrm{Cl}_{2}$ were simulated as a function of temperature for $10 \%$ of combustible and $5 \%$ of $\mathrm{O}_{2}$ diluted in nitrogen, under atmospheric pressure and for a residence time of $6 \mathrm{~s}$. Figure 9 presents the profiles of reactants for the three mixtures, and $\mathrm{CO}$, obtained during reaction of phosgene. It appears that phosgene is the most reactive fuel, as it starts to decompose at $800 \mathrm{~K}$, yielding $\mathrm{CO}$ and $\mathrm{Cl}_{2}$. $\mathrm{CO}$ is the less reactive fuel, whereas $\mathrm{CO} / \mathrm{Cl}_{2}$ reacts at intermediate temperatures thanks to the promoting effect of $\mathrm{Cl}_{2}$ and chlorine atoms as described above. Phosgene reacts promptly by thermal decomposition at a lower temperature than the beginning of $\mathrm{CO}$ consumption. In these isothermal conditions, it appears that the reactivity of the resulting mixture is very close to that of $\mathrm{CO} / \mathrm{Cl}_{2}$ used as reactants, as shown by the profile of $\mathrm{CO}$ produced from phosgene, which joins in Figure 9 the profile of $\mathrm{CO}$ in the $\mathrm{CO} / \mathrm{Cl}_{2}$ blend. This latter mixture is therefore a good phosgene surrogate from a chemical kinetics point of view, but the 
global reactivity in modeling a fire or an explosion can be different due to the strong endothermal initial pyrolysis reaction of phosgene compared to $\mathrm{CO} / \mathrm{Cl}_{2}$.

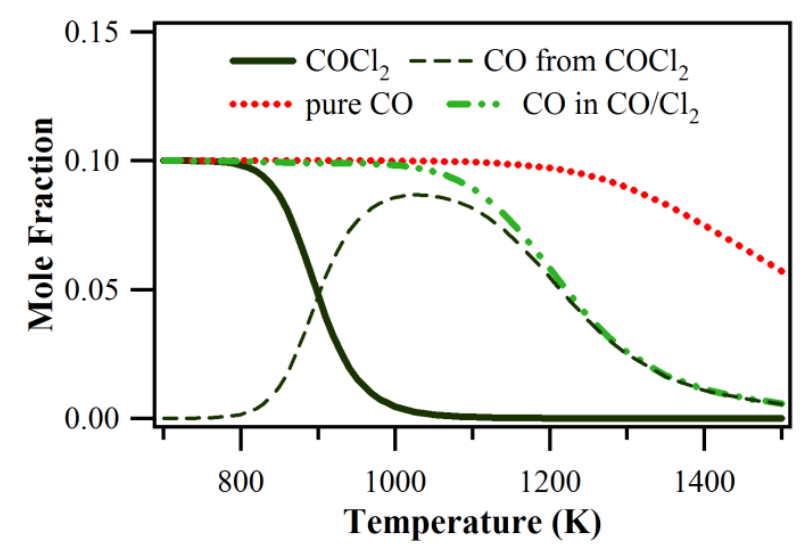

Figure 9. Oxidation of phosgene, $\mathrm{CO}$, and $\mathrm{CO} / \mathrm{Cl}_{2}$ blend in a perfectly stirred reactor. $\mathrm{P}=1 \mathrm{~atm}, \mathrm{t}=6 \mathrm{~s}$, stoichiometric conditions, dilution by nitrogen.

\section{Conclusion}

The first detailed kinetic model for the thermal decomposition and combustion of phosgene and diphosgene was developed in this work. The mechanism involves a recent validated submechanism from the literature for reactions of chlorinated species. This mechanism has been combined with a primary decomposition mechanism of phosgene including pressure effects for initial reactions, and some coupling reactions with the products of decomposition of diphosgene. A specific mechanism for the decomposition of diphosgene was proposed. Most sensitive reactions were theoretically investigated. The model reproduces well experimental results from the literature for both reactants under pyrolysis conditions in an isothermal closed reactor. The conversion and the main products are well reproduced. Around $600 \mathrm{~K}$, diphosgene is completely decomposed in these conditions, yielding mainly phosgene, and, to a lower extent, $\mathrm{CCl}_{4}$ and $\mathrm{CO}_{2}$. Phosgene starts to react above $623 \mathrm{~K}$ and solely leads to the formation of $\mathrm{CO}$ and $\mathrm{Cl}_{2}$.

Simulations in combustion showed that phosgene does not oxidize directly, but first decomposes into $\mathrm{CO}$ and chlorine by a fast pyrolysis mechanism. Ignition delay times simulated in a batch adiabatic vessel showed a late ignition for phosgene compared to $\mathrm{CO}$ and the most reactive $\mathrm{CO} / \mathrm{Cl}_{2}$ blend. This surprising low reactivity of phosgene is actually due to a freezing of the reaction caused by the endothermicity of the pyrolysis step. Conversely, isothermal simulations shown that phosgene is much more reactive than $\mathrm{CO}$ in combustion at a given temperature. Reaction products of phosgene are then similar to the $\mathrm{CO} / \mathrm{Cl}_{2}$ blend, in which $\mathrm{Cl}_{2}$ enhance the oxidation reaction thanks to a homogeneous catalytic cycle. The $\mathrm{CO} / \mathrm{Cl}_{2}$ blend can be considered as a correct surrogate for phosgene as far as thermal effects are of minor importance. 


\section{Acknowledgements}

This work was supported by DGA Maîtrise NRBC. This work was granted access to the HPC resources of IDRIS under the allocation 2017-A0010807249 made by GENCI.

\section{Supporting Information}

Supporting information contains the model including thermochemical and kinetic parameters.

\section{References}

(1) Babad, H.; Zeiler, A. G. Chemistry of Phosgene. Chem. Rev. 1973, 73, 75-91.

(2) Noort, D.; Hulst, A. G.; Fidder, A.; van Gurp, R. A.; de Jong, L. P. A.; Benschop, H. P. In Vitro Adduct Formation of Phosgene with Albumin and Hemoglobin in Human Blood. Chem. Res. Toxicol. 2000, 13, 719-726.

(3) Arce, V. B.; Della Védova, C. O.; Downs, A. J.; Parsons, S.; Romano, R. M. Trichloromethyl Chloroformate ("Diphosgene"), $\mathrm{ClC}(\mathrm{O}) \mathrm{OCCl} 3$ : Structure and Conformational Properties in the Gaseous and Condensed Phases. J. Org. Chem. 2006, 71, 3423-3428.

(4) Pitschmann, V.; Kobliha, Z.; Halámek, E.; Tusarová, I. A Simple in Situ Visual and Tristimulus Colorimetric Method for the Determination of Diphosgene in Air. J. Serbian Chem. Soc. 2007, 72, 1031-1037.

(5) Pitschmann, V.; Ivana, T.; Zbyněk, K.; David, V. Detection Tube with Composite Carrier for Detection of Phosgene and Diphosgene in Air. Hem. Ind. 2012, 66, 79-84.

(6) Gupta, R. C. Handbook of Toxicology of Chemical Warfare Agents; Academic Press, 2015.

(7) The National Institute for Occupational Safety and Health (NIOSH). CDC - The Emergency Response Safety and Health Database: Lung Damaging Agent: Phosgene (CG) https://www.cdc.gov/niosh/ershdb/EmergencyResponseCard_29750023.html (accessed Aug 31, 2017).

(8) The National Institute for Occupational Safety and Health (NIOSH). CDC - Diphosgene International Chemical Safety Cards https://www.cdc.gov/niosh/ipcsneng/neng1630.html (accessed Aug 31, 2017).

(9) Potential Military Chemical/Biological Agents and Compounds.; US Army Field Manual; FM 3-11.9.; 2005.

(10) Bunnett, J. F.; Mikolajczyk, M. Arsenic and Old Mustard: Chemical Problems in the Destruction of Old Arsenical and Mustard Munitions; Springer Science \& Business Media, 2013; Vol. 19.

(11) Brown, J. E.; Birky, M. M. Phosgene in the Thermal Decomposition Products of Poly (Vinyl Chloride): Generation, Detection and Measurement. J. Anal. Toxicol. 1980, 4, 166-174.

(12) Thomson, M. J.; Lucas, D.; Koshland, C. P.; Sawyer, R. F.; Wu, Y.-P.; Bozzelli, J. W. An Experimental and Numerical Study of the High-Temperature Oxidation of 1, 1, 1-C2H3Cl3. Combust. Flame 1994, 98, 155-169.

(13) Thomson, M. J.; Higgins, B. S.; Lucas, D.; Koshland, C. P.; Sawyer, R. F. Phosgene Formation from 1, 1, 1-Trichloroethane Oxidation. Combust. Flame 1994, 98, 350-360.

(14) Lim, K. P.; Michael, J. V. The Thermal Decomposition of $\mathrm{CH} 3 \mathrm{Cl}$ Using the Cl-atom Absorption Method and the Bimolecular Rate Constant for O+CH3 (1609-2002 K) with a Pyrolysis Photolysis-shock Tube Technique. J. Chem. Phys. 1993, 98, 3919-3928. 
(15) Michael, J. V.; Lim, K. P.; Kumaran, S. S.; Kiefer, J. H. Thermal Decomposition of Carbon Tetrachloride. J. Phys. Chem. 1993, 97, 1914-1919.

(16) Lim, K. P.; Michael, J. V. Thermal Decomposition of Phosgene. J. Phys. Chem. 1994, 98, 211-215.

(17) Christiansen J. A. Über Den Thermischen Zerfall Des Phosgens. Z. Für Phys. Chem. 1922, 103U, 99-138.

(18) Bodenstein Max; Plaut Heinrich. Bildung Und Zerfall von Phosgen in Der Wärme. Z. Für Phys. Chem. 1924, 110U, 399-416.

(19) Bodenstein, M. The Thermal and Photochemical Synthesis of Phosgene. Chem. Rev. 1930, 7 , 225-229.

(20) Battin-Leclerc, F.; Baronnet, F.; Paternotte, G.; Leclerc, J. P.; Gourhan, R. Thermal Decomposition of Chloropicrin, Diphosgene and Phosgene between 100 and 530 ${ }^{\circ}$ C. J. Anal. Appl. Pyrolysis 2000, 53, 95-105.

(21) Sirjean, B.; Lizardo-Huerta, J.-C.; Verdier, L.; Fournet, R.; Glaude, P.-A. Kinetic Modeling of the Thermal Destruction of Mustard Gas. Proc. Combust. Inst. 2017, 36, 499-506.

(22) Lizardo-Huerta, J.-C.; Sirjean, B.; Verdier, L.; Fournet, R.; Glaude, P.-A. Kinetic Modeling of the Thermal Destruction of Nitrogen Mustard Gas. J. Phys. Chem. A 2017, 121, 32543262.

(23) Montgomery, J.; Frisch, M. J.; Ochterski, J. W.; Petersson, G. A. A Complete Basis Set Model Chemistry. VI. Use of Density Functional Geometries and Frequencies. J. Chem. Phys. 1999, 110, 2822-2827.

(24) Malick, D. K.; Petersson, G. A.; Montgomery Jr, J. A. Transition States for Chemical Reactions I. Geometry and Classical Barrier Height. J. Chem. Phys. 1998, 108, 5704-5713.

(25) Frisch, M.; Trucks, G.; Schlegel, H.; Scuseria, G.; Robb, M.; Cheeseman, J.; Scalmani, G.; Barone, V.; Mennucci, B.; Petersson, G.; et al. Gaussian 09 Revision B.01; Gaussian, Inc: Wallingford CT, 2009.

(26) Lizardo-Huerta, J. C.; Sirjean, B.; Bounaceur, R.; Fournet, R. Intramolecular Effects on the Kinetics of Unimolecular Reactions of $\beta$-HOROO and HOQ ${ }^{\circ}$ OOH Radicals. Phys. Chem. Chem. Phys. 2016, 18, 12231-12251.

(27) Vansteenkiste, P.; Van Neck, D.; Van Speybroeck, V.; Waroquier, M. An Extended Hindered-Rotor Model with Incorporation of Coriolis and Vibrational-Rotational Coupling for Calculating Partition Functions and Derived Quantities. J. Chem. Phys. 2006, 124, 044314.

(28) Clinch, P. W.; Hudson, H. R. Rearrangements Occurring during the Thermal Decomposition of Alkyl Chloroformates. Chem. Commun. Lond. 1968, 15, 925-926.

(29) Lewis, E. S.; Herndon, W. C. The Decomposition of Gaseous Chloroformates. I. The Rates of Simple Alkyl Compounds1. J. Am. Chem. Soc. 1961, 83, 1955-1958.

(30) Harding, L. B.; Klippenstein, S. J.; Jasper, A. W. Ab Initio Methods for Reactive Potential Surfaces. Phys. Chem. Chem. Phys. 2007, 9, 4055-4070.

(31) Buda, F.; Bounaceur, R.; Warth, V.; Glaude, P. A.; Fournet, R.; Battin-Leclerc, F. Progress toward a Unified Detailed Kinetic Model for the Autoignition of Alkanes from C4 to C10 between 600 and 1200 K. Combust. Flame 2005, 142, 170-186.

(32) Pereira, R. C. L.; Isolani, P. C. Multiphoton Gas Phase Dissociation of Methyl and Ethyl Formates. J. Photochem. Photobiol. Chem. 1988, 42, 51-61.

(33) Francisco, J. S. Mechanistic Study of the Gas-Phase Decomposition of Methyl Formate. $J$. Am. Chem. Soc. 2003, 125, 10475-10480.

(34) Metcalfe, W. K.; Simmie, J. M.; Curran, H. J. Ab Initio Chemical Kinetics of Methyl Formate Decomposition: The Simplest Model Biodiesel. J. Phys. Chem. A 2010, 114, 54785484.

(35) Ren, W.; Lam, K.-Y.; Pyun, S. H.; Farooq, A.; Davidson, D. F.; Hanson, R. K. Shock Tube/Laser Absorption Studies of the Decomposition of Methyl Formate. Proc. Combust. Inst. 2013, 34, 453-461. 
(36) Goldfinger, P.; Letort, M.; Niclause, M. Contribution à l'étude de La Structure Moléculaire. In Volume commémoratif Victor Henri; Desoer: Liège, 1948; p 283.

(37) Leylegian, J. C.; Zhu, D. L.; Law, C. K.; Wang, H. Experiments and Numerical Simulation on the Laminar Flame Speeds of Dichloromethane and Trichloromethane. Combust. Flame 1998, 114, 285-293.

(38) Gilbert, R. G.; Luther, K.; Troe, J. Theory of Thermal Unimolecular Reactions in the Fall-off Range. II. Weak Collision Rate Constants. Berichte Bunsenges. Für Phys. Chem. 1983, 87, 169-177.

(39) Dean, A. M.; Kistiakowsky, G. B. Oxidation of Carbon Monoxide/Methane Mixtures in Shock Waves. J. Chem. Phys. 1971, 54, 1718-1725.

(40) Pelucchi, M.; Frassoldati, A.; Faravelli, T.; Ruscic, B.; Glarborg, P. High-Temperature Chemistry of $\mathrm{HCl}$ and $\mathrm{Cl} 2$. Combust. Flame 2015, 162, 2693-2704.

(41) Kee, R. J.; Rupley, F. M.; Miller, J. A. CHEMKIN-II: A FORTRAN Chemical Kinetics Package for the Analysis of Gas-Phase Chemical Kinetics. Sandia Laboratories Report, S 898009B 1993.

(42) Shapiro, J. S.; Swinbourne, E. S.; Young, B. C. The Pyrolysis of Alkyl Chlorides on the Surface of Pyrex Glass. Aust. J. Chem. 1964, 17, 1217-1228.

(43) Roesler, J. F.; Yetter, R. A.; Dryer, F. L. Inhibition and Oxidation Characteristics of Chloromethanes in Reacting CO/H2O/O2 Mixtures. Combust. Sci. Technol. 1996, 120, 1137. 